Reprod. Nutr. Dévelop., 1988, 28 Suppl. n 1, 101-102

\title{
Kinetics of in vitro fermentability of forages
}

G. PIVA, E. SANTI, S. BELLADONNA, O. CURTO $\left({ }^{*}\right)$

Ist. Scienze della Nutrizione.

(*) Universita Cattolica S. Cuore

via Emilia Parmense 84 Piacenza, Italy.

Summary. Using 41 samples of hay, silage and grass, we evaluated their fermentability in vitro using Menke's method and checking the rate of fermentation at 2-hour intervals for $26 \mathrm{~h}$. A sigmoidal model was found to be significant to illustrate the rate of fermentation of the feeds. $\mathrm{N}$-free extract $(r=0.73)$ and ADF $(r=0.66)$ were the analytic parameters of the feeds that had the greatest effect on feed fermentation. No correlation was found between gas produced and digestibility in vivo or degradability in nylon bags.

The aim of this research was to discover possible correlations between the rate of fermentation in vitro and forage composition.

Materials and methods. The experiment was carried out using 41 samples of hay (14) silage (12) and green forage (15). We determined the analytical composition, fibre components (NDF, ADF, ADL) and degradability in nylon bags after $24 \mathrm{~h}$ for each feed; digestibility was determined in vivo using sheep. The in vitro evaluations of fermentability were carried out using Menke's method (Menke et al., 1979), measuring gas and total VFA production at 2 -hour intervals for $24 \mathrm{~h}$. Six in vitro fermentations were carried out for each feed. The trend of the fermentability curves was estimated using the sigmoidal model : $y=A / 1+B^{*} x^{n}$ ( $y=$ gas produced and $x=$ hours). The parameters $A, B$ and $n$ of the curves for each feed were estimated using the method of least-squares with a linearized function and assigning a value to $\mathrm{A}$ so as to minimize the $\mathrm{Sd}$ of the regression (Spain, 1982).

Results and discussion. The model proposed was found to be significant for each feed, as seen from the analysis of the residue regressions (sum of squares = 9.05 for hay, 6.40 for silage, 11.7 for green forage). Thus, parameters $A, B$ and $n$ show feed fermentability. These parameters were found to be correlated (canonical correlation : $r 1=0.88, r 2=0.82$; the first correlation concerns $A$, the second the combination of $n$ and $B$ ) with the analytical characteristics of the feeds, and only slightly ( $r$-mult. regr. sq. $=0.32$ ) correlated with in vivo digestibility and bag degradability $(r=0.22)$. A, which estimates the maximum value of gas produced, was found to be the mostly highly correlated with feed characteristics $(r=0.63$ ) and digestibility in vivo (linear $r=0.063$ ). A depended primarily on the $N$-free extract $(r=0.73)$ and ADF $(r=0.66)$ feed values.

The sigmoidal model shows correctly the trend of in vitro degradation. The trend (parameters $A, B, n$ ) could be predicted from the chemical composition only for hays and not for green forage and silage, as shown in table 1. 
There was a correlation between gas production and VFA production in vitro $\left(\mathrm{VFA}=-0.35+3.22 \mathrm{GAS}_{24 \mathrm{~h}} ; \mathrm{r}=0.96\right)$.
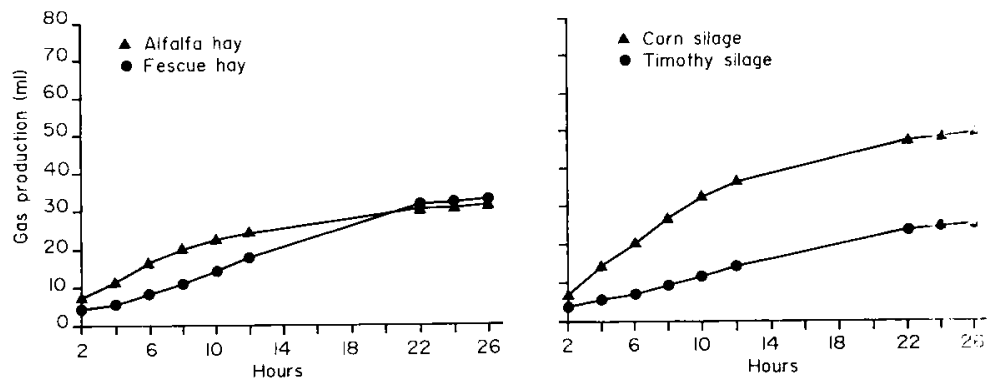

FIG. 1. - Kinetics of in vitro fermentability of some feeds.

TABL. 1. - Regression between the parameters of the curve $(A, B, n)$ and analytical parameters of feeds : correlation between $A, B, n$, and in vivo digestibility $\left(\mathrm{d}_{\mathrm{vivo}}\right)$ and in sacco $\left(\mathrm{d}_{\mathrm{sacco}}\right)$ degradibility of green forage $(\mathrm{G})$, hay $(\mathrm{H})$, silage $(\mathrm{S})$ and total feeds $(\mathrm{T})$.

\begin{tabular}{|c|c|c|c|c|c|c|c|c|c|c|c|c|}
\hline & $\bar{x}$ & $d_{\text {sacco }}$ & $d_{\text {vivo }}$ & const. & $\mathrm{CP}$ & $\mathrm{EE}$ & $\mathrm{CF}$ & NFE & NDF & $A D F$ & $A D L$ & $r^{2}$ \\
\hline \multirow{4}{*}{$\begin{array}{c}A \mathrm{G} \\
\mathrm{H} \\
\mathrm{S} \\
\mathrm{T}\end{array}$} & 7 & 0.45 & 0.61 & 5 & - & & & - & - & $\ldots$ & - & 0.3 \\
\hline & 4 & & 30 & 96.31 & -2.14 & - & 0.31 & - & -0.46 & - & & \\
\hline & 62.83 & 0.64 & 0.72 & & & & & & & & & \\
\hline & 54.93 & 0.37 & 0.63 & 3.11 & 0.32 & 1.42 & 0.94 & 1.20 & 0.32 & 0.37 & 0.47 & 0.6 \\
\hline \multirow[b]{4}{*}{ T } & 32.16 & -0.55 & -0.2 & & & & & & & & & \\
\hline & 23.25 & 0.35 & & 128 & 3.32 & 6.98 & - & & 2 & - & - & 0.9 \\
\hline & 31.00 & -0 & -0 & & & & - & -1 & - & - & - & \\
\hline & 28.58 & -0.37 & -0.1 & 1003.88 & -14.07 & -11.79 & -8.34 & $-s$ & 0.15 & -2.15 & 0.37 & 0.3 \\
\hline \multirow{4}{*}{ T } & 1 & & & & 0.03 & - & - & - & - & - & - & 0.2 \\
\hline & 1 & & -0. & 3 & - & - & -1.82 & 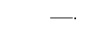 & $\ldots$ & $\ldots$ & 2.62 & \\
\hline & -1.26 & 0. & 0. & 0. & - & - & - & - & 0. & - & - & 0.2 \\
\hline & -1.20 & 0.42 & 0.07 & 5.41 & 0.06 & 0.04 & 0.04 & 0.04 & 0.01 & 0.02 & - & 0. \\
\hline
\end{tabular}

$=$ coefficient not determinated by the regression model.

Acknowledgments. - Research work supported by M.P.I., Italy, Project $40 \%$.

Menke K. H., Raab L., Salewski A., Steingass H., Fritz D., Schneider W., 1979. J. agric. Sci. Camb.,93, 217-222.

Spain J. D., 1982. Basic microcomputers models in biology. Addison-Wesley Publ. Co. Reading (Massachusetts) USA. 